Piyush Ingale, Chengyue Guan, Ralph Kraehnert, Raoul Naumann d'Alnoncourt, Arne Thomas, Frank Rosowski

\title{
Design of an active and stable catalyst for dry reforming of methane via molecular layer deposition
}

Journal article | Accepted manuscript (Postprint)

This version is available at https://doi.org/10.14279/depositonce-11360

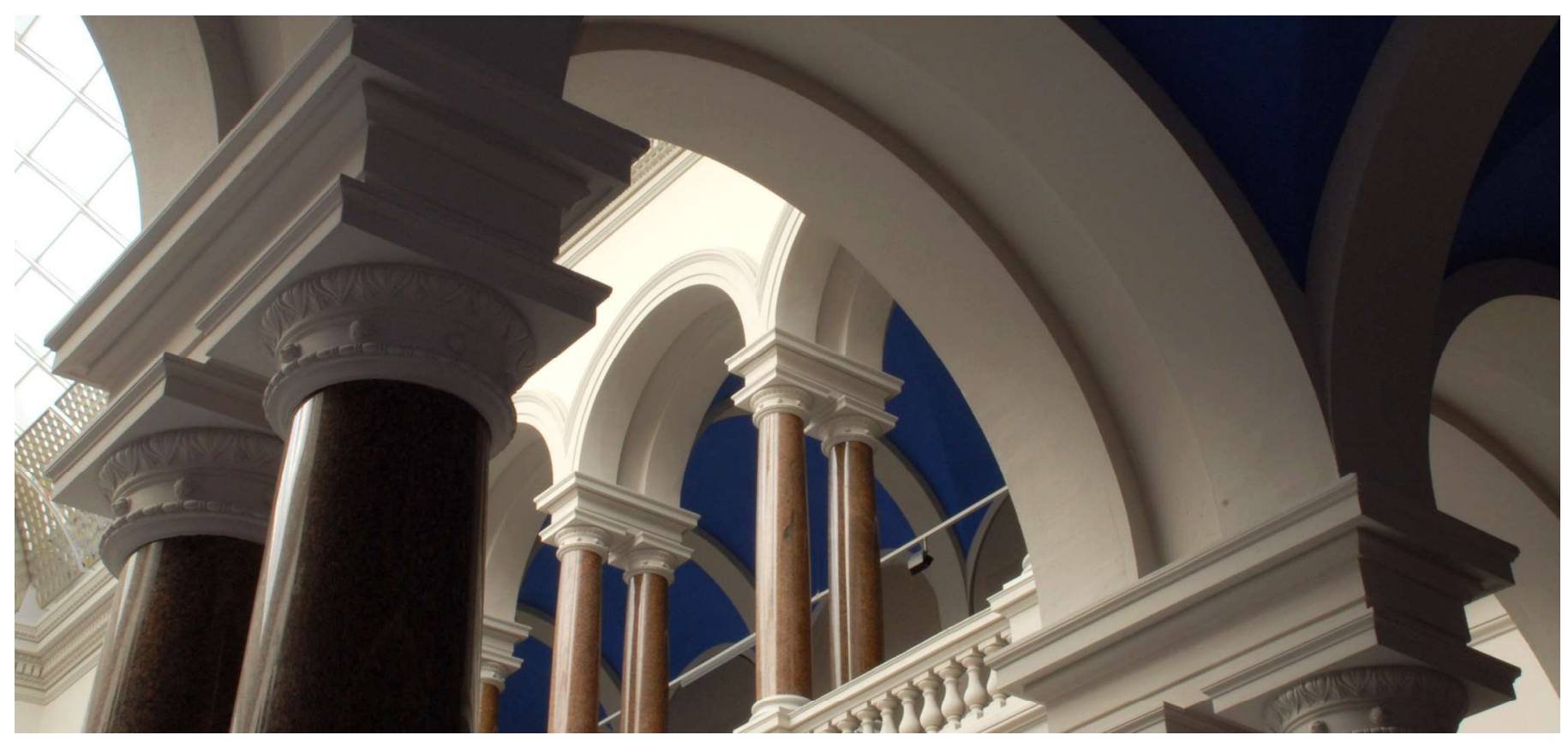

Ingale, P., Guan, C., Kraehnert, R., Naumann d'Alnoncourt, R., Thomas, A., \& Rosowski, F. (2021).

Design of an active and stable catalyst for dry reforming of methane via molecular layer deposition.

Catalysis Today, 362, 47-54. https://doi.org/10.1016/j.cattod.2020.04.050 


\section{Design of an active and stable catalyst for dry reforming of methane}

via molecular layer deposition

Piyush Ingale a, Chengyue Guan a, Ralph Kraehnert a, Raoul Naumann d'Alnoncourt $a^{*}$, Arne Thomas ${ }^{b}$, and Frank Rosowski ${ }^{a, c}$

a BasCat - UniCat BASF JointLab, Technische Universität Berlin, Berlin 10623, Germany

${ }^{\mathrm{b}}$ Functional Materials, Department of Chemistry, Technische Universität Berlin, Berlin 10623, Germany

c BASF SE, Process Research and Chemical Engineering, Heterogeneous catalysis, Ludwigshafen 67056, Germany

^r.naumann@bascat.tu-berlin.de 


\section{Abstract}

The dry reforming of methane (DRM) has been proposed as an efficient way to convert two greenhouse gases, namely $\mathrm{CO}_{2}$ and $\mathrm{CH}_{4}$ to syngas. However, most catalysts reported in the literature suffer from strong deactivation during the reforming reaction. The deactivation is caused by strong sintering of catalytically active nanoparticles and the formation of filamentous carbon. Herein a new synthesis procedure based on molecular layer deposition (MLD) is established to stabilize DRM catalysts under reaction conditions. Deactivation of a $\mathrm{Ni} / \mathrm{SiO}_{2}$ reference catalyst was prevented by forming a defined porous net-like over-layer, which prevents the sintering and detachment of Ni nanoparticles by filamentous carbon. The MLD approach was further compared to the formation of an overlayer by atomic layer deposition (ALD), demonstrating the advantages of MLD forming hybrid organic-inorganic alucone layers over classical alumina ALD.

Keywords: Atomic layer deposition, Molecular layer deposition, Dre reforming of methane, Ni catalyst, Coke resistant, Sinter-stable.

\section{Introduction}

Rapid increase in population and industrialization has led to rising dependence on fossil fuels to satisfy the continuously increasing energy demand. With depletion of these fossil fuels, methane has become attractive due to its larger reserves, discovery of shale gas and sustainable production from fermented wastes [1,2]. Synthesis gas (a mixture of $\mathrm{CO}$ and $\mathrm{H}_{2}$ ) is a major feedstock in production of intermediates and numerous chemicals such as Fischer Tropsch chemicals, methanol, dimethyl ether, acetic acid and formic acid [3,4]. Syngas can be produced by reforming reactions of methane such as steam reforming, autothermal reforming, partial oxidation and dry reforming. Steam reforming of methane has been utilized in industry for decades but still has drawbacks in terms of its endothermic nature and $\mathrm{H}_{2} / \mathrm{CO}$ ratio of $3: 1$ which is higher than needed for Fischer Tropsch synthesis [5-7].

Dry reforming of methane has been widely investigated since it utilizes the two greenhouse gases (methane and carbon dioxide) as feedstock to convert them into economically more valuable synthesis gas. DRM yields syngas with lower $\mathrm{H}_{2} / \mathrm{CO}$ ratio which makes it preferable for Fischer Tropsch synthesis processes to produce long chain hydrocarbons [8,9]. Various supported metal catalysts such as Rh [10], Pt [11], 
Ir [12], Pd [13] , Ru [14], Ni [15] have been reported to catalyse the DRM reaction. Due to limited availability and higher costs, $\mathrm{Ni}$ based catalysts are desirable over noble metal catalysts $[16,17]$. Recently BASF with its partner Linde has developed a Nibased catalyst for dry reforming of methane $[18,19]$. However, Ni nanoparticles (NPs) used in dry reforming of methane reaction suffer from severe deactivation. The deactivation of nickel-based catalyst is governed by two major phenomena, namely coke deposition [20] and sintering [21]. Coke formation can be overcome by higher reaction temperatures as well as smaller Ni particle size, however, high temperature operations are deemed to be energy intensive and increase the rate of sintering of catalyst $[22,23]$. The sintering of small supported metallic nanoparticles can be avoided by encapsulating it with an oxide shell [24]. Various methods for encapsulation have been studied which includes sol gel synthesis [25], chemical vapour deposition [26] and atomic layer deposition [27]. However, in most cases the stability comes at expense of reduced activity due to mass transportation limitation.

Atomic Layer Deposition (ALD) or Molecular Layer Deposition (MLD) are vapour phase deposition processes with a self-limiting nature through chemical reactions between the surface functionality and the reactant precursors [28]. ALD is used for deposition of inorganic thin films (e.g. $\mathrm{Al}_{2} \mathrm{O}_{3}, \mathrm{ZnO}, \mathrm{TiO}_{2}$ ) [29], while MLD can deposit hybrid inorganic organic thin films (e.g. Alucone or Zincone) [30]. ALD and MLD provide numerous advantages over traditional coating methods due to the high conformity of the deposited layers resulting from the utilization of maximum support surface area. ALD/MLD has been successively employed in catalysis research for the stabilization of catalysts. Feng et al.[31] , demonstrated that a single $\mathrm{Al}_{2} \mathrm{O}_{3} \mathrm{ALD}$ cycle was enough to suppress the sintering of $\mathrm{Pd}$ nanoparticles for $6 \mathrm{~h}$ at $270^{\circ} \mathrm{C}$ under methanol decomposition reaction conditions. Lu et al.[32], showed that $\mathrm{Pd} / \mathrm{Al}_{2} \mathrm{O}_{3}$ catalyst can be stabilized under oxidative dehydrogenation of ethane conditions after 45 cycles of $\mathrm{Al}_{2} \mathrm{O}_{3} \mathrm{ALD}$, however, prior thermal treatment was necessary to induce porosity within the overcoat layer. Thermal treatment at $700^{\circ} \mathrm{C}$ was necessary for the generation of pore size of $\sim 2 \mathrm{~nm}$ in overcoat layer while gradually restoring accessibility to the Pd nanoparticles. Baktash et al. [33] utilized an "inverse catalyst" approach and coated bare $\mathrm{NiO}$ nanopowder with a thin $\mathrm{Al}_{2} \mathrm{O}_{3}$ layer for its stabilization under dry reforming of methane conditions. The catalyst prepared with 5 cycles of $\mathrm{Al}_{2} \mathrm{O}_{3} \mathrm{ALD}$ showed enhanced stability compared to the bare NiO nanopowder. Liang 
et al. [34] [35] utilised an innovative approach to form a microporous mesoporous layer on silica particles using the molecular layer deposition of aluminium alkoxide followed by either etching with water or calcination in air at high temperature. Gould et. al. [36] deposited small $\mathrm{Ni}$ nanoparticles $\left(\sim 3 \mathrm{~nm}\right.$ ) via ALD processes on $\mathrm{Al}_{2} \mathrm{O}_{3}$ support and applied an aluminium alkoxide over-layer on them using molecular layer deposition of TMA, ethanolamine (EA), and maleic anhydride (MA), i.e. an ABC type MLD. They successfully stabilized $\mathrm{Ni}$ nanoparticles under DRM conditions, however, the highest reaction temperature applied was $700^{\circ} \mathrm{C}$. Gould et al. hypothesized that longer block chain is needed in order to stabilize the metal nanoparticles under reaction conditions while keeping their activity intact to overcome mass transfer limitation. We used simple chemistry of $A B$ type molecular layer deposition process to demonstrate the enhancement in stability and activity of catalysts under dry reforming conditions at variable temperatures from as low as $500^{\circ} \mathrm{C}$ to as high as $800^{\circ} \mathrm{C}$.

Herein we report the preparation of inorganic alumina as well as hybrid inorganicorganic alucone coated $\mathrm{NiO} / \mathrm{SiO}_{2}$ catalysts using atomic and molecular layer deposition. We utilized simpler AB type chemistry for the ALD $\left(T M A / H_{2} \mathrm{O}\right)$ and MLD (TMA/Ethylene glycol). Mesoporous $\mathrm{SiO}_{2}$ was used as catalyst support due to its high surface area and internal porosity. Silica gel was chosen in order to eliminate any stabilization effect that may arise due to stronger metal support interaction between $\mathrm{Ni}$ nanoparticles and $\mathrm{Al}_{2} \mathrm{O}_{3}$. The effect of the inorganic and hybrid organic-inorganic overcoat layers on stability and activity of $\mathrm{Ni} / \mathrm{SiO}_{2}$ was evaluated. Application of the inorganic organic hybrid protective layers on $\mathrm{Ni} / \mathrm{SiO}_{2}$ resulted in a catalyst that is highly active and stable against coke formation under harsh DRM conditions.

\section{Experimental Section}

Silica powder $\left[\mathrm{SiO}_{2}\right.$, high-purity grade. $\geq 99 \%$ (Davisil Grade 636 ), average pore size $60 \AA$, 35-60 mesh particle size, Sigma-Aldrich, specific surface area $506 \mathrm{~m} 2 / \mathrm{g}$ ] was used as substrate and support for catalyst. $\mathrm{Ni}\left(\mathrm{NO}_{3}\right)_{2} .6 \mathrm{H}_{2} \mathrm{O}[99.999 \%$ trace metal basis] and ethylene glycol [spectrophotometric grade, $\geq 99 \%$ ] were purchased from Sigma Aldrich. Trimethylaluminum $\left[\mathrm{Al}\left(\mathrm{CH}_{3}\right)_{3}\right.$, TMA, elec. gr., 99.999\% Al] and water $\left(\mathrm{H}_{2} \mathrm{O}, \mathrm{CHROMASOLV} \circledast\right.$, for HPLC, Riedel-de Haen) served as precursors and were used without further purification. High purity $\mathrm{N}_{2}$, Ar, and $\mathrm{He}$ (99.999\%) were used as carrier and purging gases. 


\subsection{Synthesis of $5 \mathrm{wt} \% \mathrm{NiO} / \mathrm{SiO}_{2}$}

Nickel supported on silica was prepared by using incipient wetness impregnation method reported elsewhere [37]. The metal loading of Nickel was set to 5 wt.\%. In typical synthesis procedure, defined amount of nickel nitrate $\left(\mathrm{Ni}\left(\mathrm{NO}_{3}\right)_{2} .6 \mathrm{H}_{2} \mathrm{O}\right)$ and ethylene glycol was dissolved in HPLC grade water and stirred at $400 \mathrm{rpm}$ for $30 \mathrm{~min}$. The molar Ni/EG ratio was 1 and volume of water used was equal to the pore volume of silica support powder. The metal salt solution was dropwise added to the silica support and mixed thoroughly. After that sample was kept standing overnight at room temperature, followed by drying at $70^{\circ} \mathrm{C}$ for $24 \mathrm{~h}$. Finally, the sample was calcined at $550^{\circ} \mathrm{C}$ for $4 \mathrm{~h}$ with heating rate of $10^{\circ} \mathrm{C} / \mathrm{min}$ under 500 $\mathrm{ml} / \mathrm{min}$ of $20 \% \mathrm{O}_{2} / \mathrm{N}_{2}$ atmosphere. This $\mathrm{NiO} / \mathrm{SiO}_{2}$ is used as catalyst precursor and base material for further ALD experiments.

\subsection{Atomic layer deposition of AlOx overlayer}

Atomic layer deposition experiments were conducted in home build set-up. The detailed description of set-up is reported elsewhere [38]. AlOx coating on $\mathrm{NiO} / \mathrm{SiO}_{2}$ powder was carried out in magnetic suspension balance followed by scale up in fixed bed reactor. $5 \mathrm{wt} . \% \mathrm{NiO} / \mathrm{SiO}_{2}$ powder was filled into quartz fixed bed reactor. The ALD was carried out under continuous total gas flow of $50 \mathrm{ml} / \mathrm{min}$ at atmospheric pressure. TMA saturator was heated to $50^{\circ} \mathrm{C}$ while water saturate was kept at room temperature. Precursors and reactant in this ALD experiment were sequentially introduced into the reactor with continuous flow of $25 \mathrm{~mL} / \mathrm{min}$ carrier gas. The sequence used was TMA $/ \mathrm{N}_{2}$ - Ar purge - $\mathrm{H}_{2} \mathrm{O} / \mathrm{He}$ - Ar purge. Typical half cycle time were determined based in-situ mass spectrometry data. Precursor was dosed to reactor until saturation of TMA signal (m/z: 57) was observed. Valve switching between the ALD sequences was done manually. Fixed bed was divided into two segments by quartz wool and after every 3 cycles of $\mathrm{AIO}_{x} \mathrm{ALD}$ one segment was taken out. In total 3 and 6 cycles of $\mathrm{AIO} \times \mathrm{ALD}$ on $\mathrm{NiO} / \mathrm{SiO}_{2}$ were carried out.

\subsection{Molecular layer deposition of alucone overlayer}

Molecular layer deposition experiments were also conducted in similar home build set-up. Initially alucone coating on $\mathrm{NiO} / \mathrm{SiO}_{2}$ powder was carried out in magnetic suspension balance followed by scale up in fixed bed reactor. Approximately $100 \mathrm{mg}$ of $5 \mathrm{wt} \% \mathrm{NiO} / \mathrm{SiO}_{2}$ was filled into special crucible designed for magnetic suspension 
balance. The MLD was carried out under continuous total gas flow of $50 \mathrm{ml} / \mathrm{min}$ at atmospheric pressure. TMA saturator was heated to $50^{\circ} \mathrm{C}$ while ethylene glycol (EG) was saturated at $80^{\circ} \mathrm{C}$. Precursors and reactant in this MLD experiment were sequentially introduced in to reactor with continuous flow of carrier gas. The sequence used was $\mathrm{TMA} / \mathrm{N}_{2}$ - Ar purge - EG/He - Ar purge. Typical half cycle time were determined based in-situ mass balance data. Precursor was dosed to reactor until saturation in mass gain was achieved. Mass changes were in situ monitored by gravimetric mass balance every $15 \mathrm{~min}$ for $5 \mathrm{~min}$ during the experiment. Valve switching between the MLD sequences was done manually. Afterwards the system was scaled up in fixed bed reactor with quartz tube $(\sim 30 \mathrm{~mL}$ volume), the self-limiting nature of MLD process and cycle times were determined based on the in-situ mass spectrometry data. Fixed bed was divided into two segments by quartz wool and after every 3 cycles of alucone MLD one segment was taken out. In total 3 and 6 cycles of alucone $\mathrm{MLD}$ on $5 \mathrm{wt} \% \mathrm{NiO} / \mathrm{SiO}_{2}$ were carried out.

\subsection{Characterization of catalysts}

Nitrogen sorption analysis was performed at $77 \mathrm{~K}$ using a Quadrasorb SI device manufactured by Quantachrome, and the samples were degassed at $120^{\circ} \mathrm{C}$ for $12 \mathrm{~h}$ prior to measurements. The surface area was determined by the Brunauer-EmmettTeller (BET) method, and the corresponding pore size distribution was obtained by the NLDFT method ( $\mathrm{N}_{2}$ at $77 \mathrm{~K}$ on silica with cylindrical pore, adsorption branch model). Xray powder diffraction (XRD) patterns were recorded on Brucker $\mathrm{D} 8$ diffractometer with $\mathrm{Cu}$ Ka1 radiation $(\lambda=0.154 \mathrm{~nm})$ equipped with scintillation counter. Transmission electron microscopy (TEM) images of as synthesized and spent catalysts were collected on FEI Tecnai G2 20 S-TWIN electron microscope equipped with an energy dispersive X-ray detector operated at 200kV. XPS of as synthesised samples (without any thermal treatment) was measured on K-Alpha ${ }^{\mathrm{TM}}+\mathrm{X}$-ray Photoelectron Spectrometer (XPS) System (Thermo Scientific), with Hemispheric $180^{\circ}$ dual-focus analyser with 128-channel detector. X-ray monochromator is Micro focused Al-Ka radiation. For the measurement, the as-prepared samples were directly loaded on the sample holder for measurement. The data was collected with X-ray spot size of 200 $\mu \mathrm{m}, 20$ scans for survey, and 50 scans for regions. All peaks were calibrated by setting the $\mathrm{BE}$ for adventitious carbon peak $\mathrm{C} 1 \mathrm{~s}$ to $284.8 \mathrm{eV}$ to compensate for the charging effect. The X-ray fluorescence spectroscopy (XRF) was performed in a Bruker S4 
Pioneer X-ray spectrometer. Sample preparation by melted pellets (100 $\mathrm{mg}$ sample with $8.9 \mathrm{~g}$ of $\mathrm{Li}_{2} \mathrm{~B}_{4} \mathrm{O}_{7}$ ). $\mathrm{CHN}$ analysis was carried out on spent catalyst for determination of carbon content after catalysis in Thermo FlashEA 1112 Organic Elemental Analyser. TG-MS experiments were carried out in a thermal gravimetric analysis system based on the magnetic suspension balance with vertical geometry designed by Rubotherm. The exhaust gas from TG unit was analysed with quadrupole mass spectrometer (Pfeiffer PrismaPlus QMA 220) with a gastight ion source and a heated segregation-free capillary gas inlet.

\section{Catalytic experiments}

The catalytic experiments were carried out in 8-bed parallel high throughput set-up designed by ILS. In the catalytic test, $15 \mathrm{mg}$ of catalyst mix well with $45 \mathrm{mg} \mathrm{SiO}_{2}$ to fill in the quartz tube reactors. The catalysts are first in situ reduced with $5 \% \mathrm{H}_{2}$ and $95 \% \mathrm{~N}_{2}$ at $500^{\circ} \mathrm{C}$ for $1 \mathrm{~h}$. The reducing gas is flushed out with $\mathrm{N}_{2}$ for $10 \mathrm{~min}$. After this, the reaction feed is dosed into the reactors. The feed composition is $10 \% \mathrm{CH}_{4}$, $10 \% \mathrm{CO}_{2}, 10 \% \mathrm{~N}_{2}$ and $70 \% \mathrm{He}$. The reaction temperature is $500,600,700$, and $800^{\circ} \mathrm{C}$, and each reaction temperature lasts $5 \mathrm{~h}$, and $10 \mathrm{~h}$ at $800^{\circ} \mathrm{C}$. After the whole test, the reactors are cooled down in $\mathrm{N}_{2}$ to room temperature. The products leaving reactors were analysed by Agilent gas chromatography.

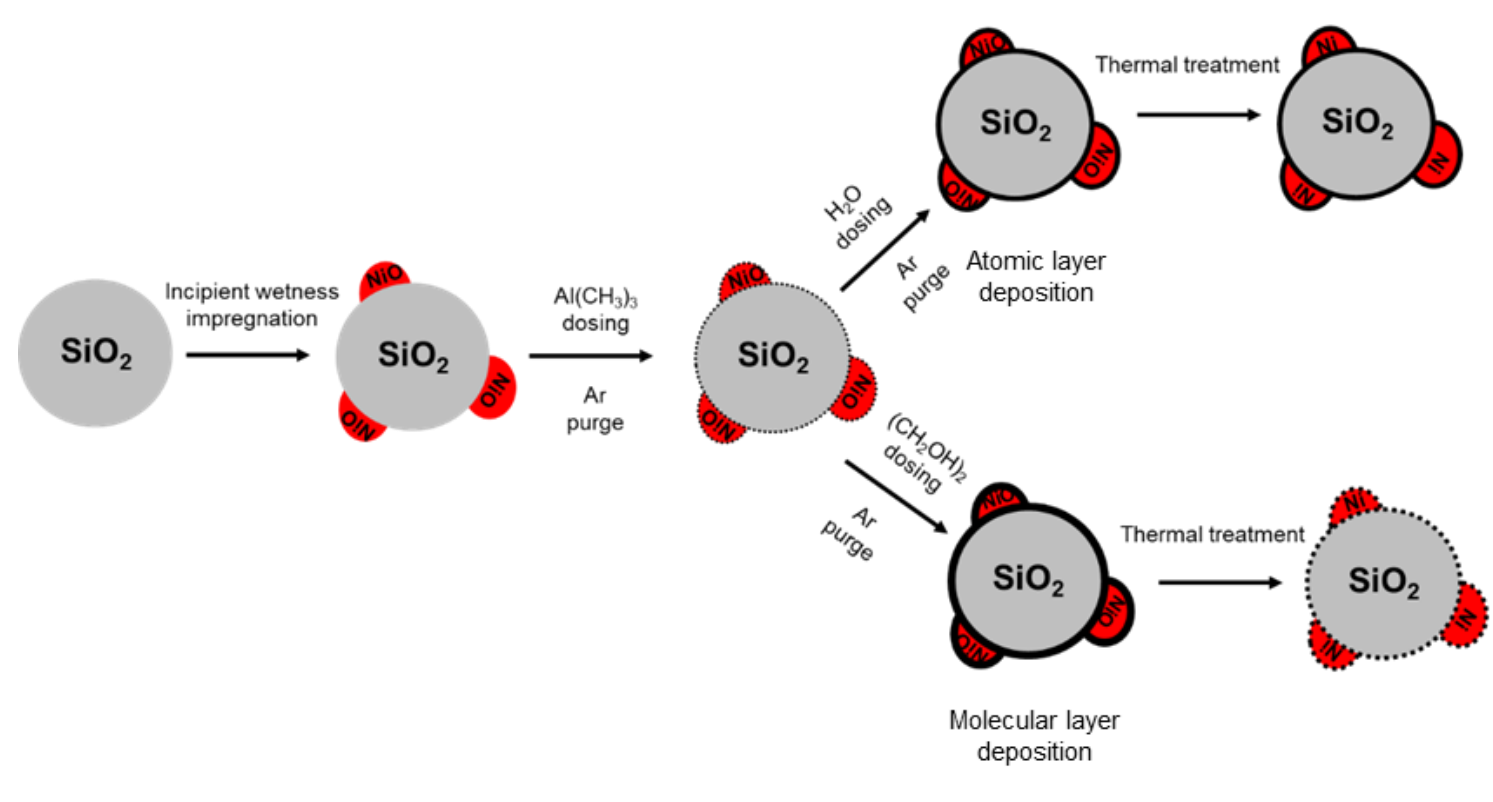

Figure 1. Strategy for synthesis of ALD and MLD coated catalysts for dry reforming of methane. 


\section{Results and Discussion}

\subsection{Synthesis approach}

The synthetic approaches used in this study are summarized in Figure 1. NiO nanoparticles supported on the high surface area silica gel were successfully prepared by incipient wetness impregnation. The $\mathrm{NiO}$ nanoparticles are precursors for the active $\mathrm{Ni}^{\circ}$ species formed when the alumina/alucone overcoated $\mathrm{NiO} / \mathrm{SiO}_{2}$ were reduced at $500^{\circ} \mathrm{C}$ in $5 \% \mathrm{H}_{2}$ stream for $1 \mathrm{~h}$ prior to reaction in the reactor. 3 and 6 cycles of alumina and alucone over-layers were successfully applied by an AB type ALD and MLD process respectively. Alumina ALD is a widely investigated process, where during the first half cycle trimethylaluminum (TMA) reacts with surface hydroxyl groups forming surface chemisorbed $\mathrm{Al}\left(\mathrm{CH}_{3}\right)_{\times}$species, while during the second half cycle $\mathrm{H}_{2} \mathrm{O}$ is exposed to the ALD reactor forming $\mathrm{Al}(\mathrm{OH})_{\times}$species with $\mathrm{CH}_{4}$ as leaving group. The reaction will continue until one surface monolayer is formed and/or all surface groups are saturated. The ALD reaction was carried out at the deposition temperature of $150^{\circ} \mathrm{C}$. The detailed process description and growth characteristics via in-situ mass gain analysis of alumina ALD on high surface area silica gel is explained elsewhere.[39] During Alucone MLD, the first half cycle is similar to alumina ALD. However, during the second half cycle, ethylene glycol is dosed into the deposition reactor instead of $\mathrm{H}_{2} \mathrm{O}$. Ethylene glycol reacts with surface $\mathrm{Al}\left(\mathrm{CH}_{3}\right)_{\times}$species to form aluminium alkoxide hybrid polymeric species. The MLD reaction was carried out at $150^{\circ} \mathrm{C}$ and ethylene glycol was saturated in He as carrier gas at $80^{\circ} \mathrm{C}$.

\subsection{Characterization}

\subsubsection{Inorganic alumina over-layer via ALD synthesis}

$\mathrm{N}_{2}$ sorption measurements were carried out on both pristine and ALD modified samples. The surface area of all ALD coated samples decreased drastically with increasing ALD cycle number. The adsorption-desorption isotherms are shown in figure 2a. For the pristine silica and all ALD coated samples type IV isotherms with H1 hysteresis loops are observed indicating the conformal coating of the mesopores of the porous silica by alumina layers. The pore sizes measured by NLDFT changed from $6.6 \mathrm{~nm}$ to $3.6 \mathrm{~nm}$ after 6 ALD cycles. The change in surface area and pore size is in agreement with the detailed ALD study on the growth of alumina layers on mesoporous silica studies by Strempel et al. [39] The Al content increased from 0 to $13.7 \%$ after 3 ALD cycles and to $19.2 \%$ after 6 ALD cycles. This is expected, as the 
uptake of aluminium will decrease with the number of ALD cycles due to the reduced surface area of the substrate after each cycle.
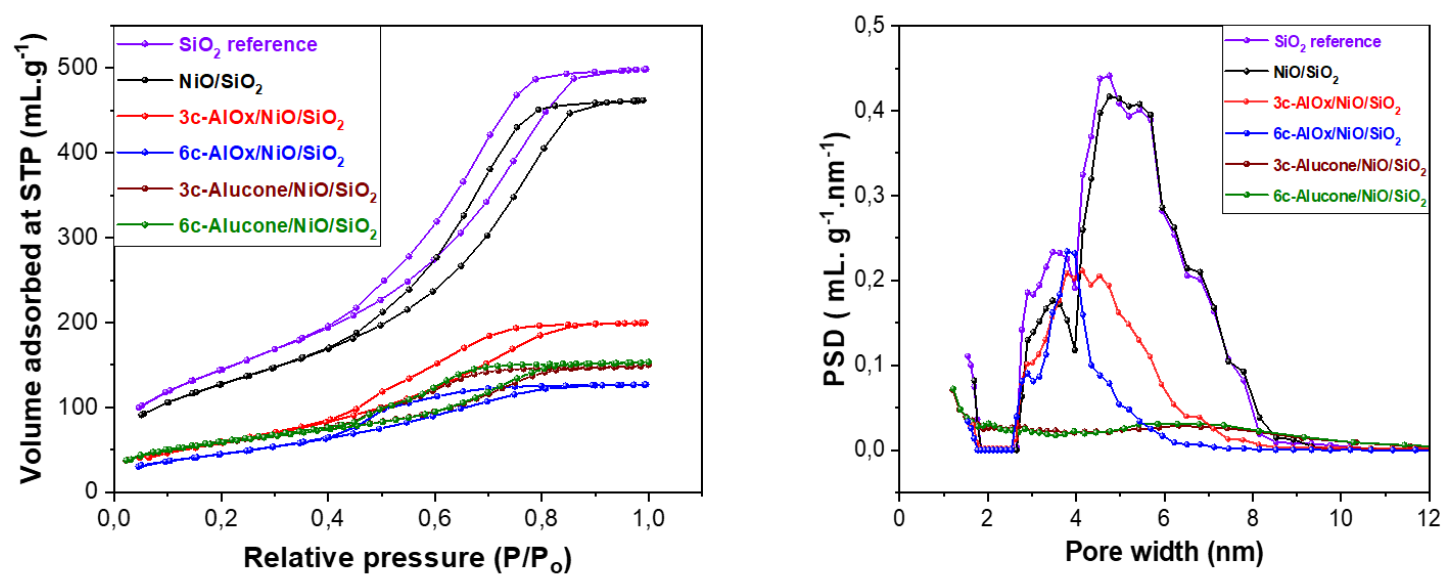

Figure 2 (a) $\mathrm{N}_{2}$ sorption isotherms of silica, reference $\mathrm{NiO} / \mathrm{SiO}_{2}$ and $\mathrm{ALD} / \mathrm{MLD}$ modified materials, (b) pore size distribution calculated from NLDFT method

Powder XRD measurements of the pristine, ALD coated samples are shown in figure S1. No distinct features can be seen in all measurements. However, a broad peak at $2 \theta: 43.2^{\circ}$ in the $\mathrm{X}$-ray diffraction patterns of the $\mathrm{NiO} / \mathrm{SiO}_{2}$ sample calcined at $550^{\circ} \mathrm{C}$ can be attributed to the (200) reflection of cubic NiO. The broad peak of this reflection indicate that very small $\mathrm{NiO}$ nanoparticles are stabilized on the porous silica support. The ALD coated samples did not show any significant change in the diffraction patterns as compared to their parent material, showing that the alumina layers are amorphous. HRTEM images (figure 4a) are revealing the presence of highly dispersed and well impregnated $\mathrm{NiO}$ nanoparticles, with a size well below $\sim 5 \mathrm{~nm}$. After coating with ALD, the alumina overlayers are hardly visible as expected for a very thin amorphous coating of alumina on an amorphous silica substrate. X-ray photoelectron spectroscopy (XPS) (figure 3) show $\mathrm{Ni}^{2+}$ in the non-coated $\mathrm{NiO} / \mathrm{SiO}_{2}$ material with a binding energy of $855.5 \mathrm{eV}$. After deposition of alumina, two peaks appear at binding energies of $852.4 \mathrm{eV}$ and $856.4 \mathrm{eV}$. The peak at $852.4 \mathrm{eV}$ correspond to the presence of metallic $\mathrm{Ni}^{\circ}$ species in ALD coated samples, indicating that $\mathrm{Ni}^{2+}$ species are being reduced during the ALD process. It can be assumed that either TMA or leaving methyl groups after chemisorption of TMA act as reducing agent. The peak at BE of $856.4 \mathrm{eV}$ 
corresponds to $\mathrm{Ni}^{2+}$ with a positive shift either due to strong metal support interaction between $\mathrm{Ni}$ and $\mathrm{AlO}_{x}$ or the formation of $\mathrm{NiAl}_{2} \mathrm{O}_{4}$. Littlewood et al. [40], hypothesized that deposition of amorphous alumina on $\mathrm{NiO}$ via ALD, led to the formation of $\mathrm{NiAl}_{2} \mathrm{O}_{4}$. This new phase cannot be detected by $\mathrm{p}-\mathrm{XRD}$, due to small crystallite size and density as also evident from our study.

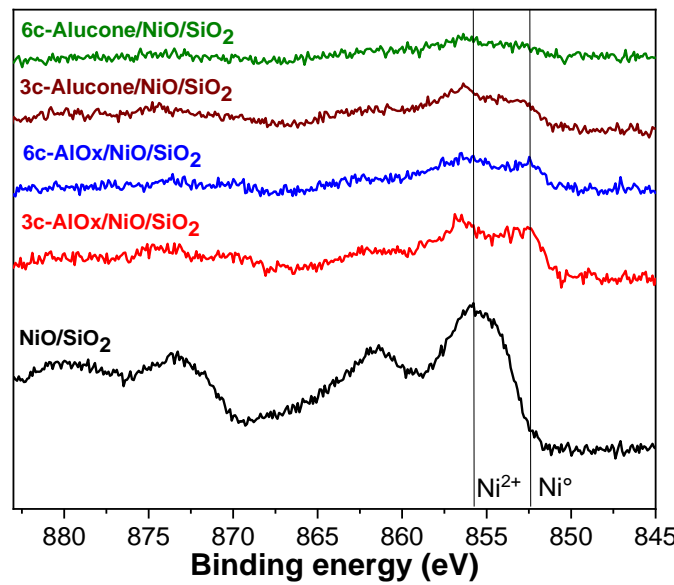

Figure 3. XPS analysis of $\mathrm{NiO} / \mathrm{SiO}_{2}$ and $\mathrm{ALD} / \mathrm{MLD}$ modified materials

XRF measurements (table 1) reveal that the $\mathrm{Ni}$ loading in the samples decreases as the number of ALD cycles increase. The initial loading of parent $\mathrm{NiO} / \mathrm{SiO}_{2}$ was kept at 5 wt. \% Ni. During ALD process as $\mathrm{AlO}$ x layers were deposited on to parent $\mathrm{NiO} / \mathrm{SiO}_{2}$ the overall $\mathrm{Ni}$ content on $\mathrm{AlO}$ x coated $\mathrm{NiO} / \mathrm{SiO}_{2}$ decreased however, Si/Ni ratio was constant throughout all of the samples.

Table 1. Physiochemical analysis of as synthesized ALD and MLD modified DRM catalysts

\begin{tabular}{|c|c|c|c|c|c|c|c|c|c|}
\hline \multirow[t]{2}{*}{ Sample } & \multicolumn{2}{|c|}{$\begin{array}{l}\text { Surface area [a] } \\
\qquad\left(\mathrm{m}^{2} / \mathrm{g}\right)\end{array}$} & \multicolumn{2}{|c|}{$\begin{array}{l}\text { Pore size [b] } \\
\quad(\mathrm{nm})\end{array}$} & \multicolumn{2}{|c|}{$\begin{array}{l}\text { Pore Volume [b] } \\
\quad(\mathrm{cc} / \mathrm{g})\end{array}$} & \multirow{2}{*}{$\begin{array}{c}\mathrm{Ni} \\
\text { content } \\
{[\mathrm{d}]} \\
(\%)\end{array}$} & \multirow{2}{*}{$\begin{array}{c}\text { Al } \\
\text { content } \\
{[d]} \\
(\%)\end{array}$} & \multirow[t]{2}{*}{$\begin{array}{l}\mathrm{Si} / \mathrm{Ni} \\
\text { ratio }\end{array}$} \\
\hline & $\begin{array}{l}\text { Before } \\
\text { thermal } \\
\text { treatment }\end{array}$ & $\begin{array}{l}\text { After } \\
\text { thermal } \\
\text { treatment } \\
\text { [c] }\end{array}$ & $\begin{array}{l}\text { Before } \\
\text { thermal } \\
\text { treatment }\end{array}$ & $\begin{array}{l}\text { After } \\
\text { thermal } \\
\text { treatment } \\
\text { [c] }\end{array}$ & $\begin{array}{l}\text { Before } \\
\text { thermal } \\
\text { treatment }\end{array}$ & $\begin{array}{l}\text { After } \\
\text { thermal } \\
\text { treatment } \\
\text { [c] }\end{array}$ & & & \\
\hline $\mathrm{SiO}_{2}$ & 505 & $\mathrm{~N} / \mathrm{A}$ & 6.6 & $\mathrm{~N} / \mathrm{A}$ & 0.75 & $\mathrm{~N} / \mathrm{A}$ & 0 & 0 & - \\
\hline $\mathrm{Ni} / \mathrm{SiO}_{2}$ & 465 & N/A & 5.5 & $\mathrm{~N} / \mathrm{A}$ & 0.7 & $\mathrm{~N} / \mathrm{A}$ & 5 & 0 & 8.6 \\
\hline $\begin{array}{l}3 \mathrm{c}-\mathrm{AlOx} / \mathrm{Ni} / \mathrm{SiO}_{2} \\
\text { (ALD) }\end{array}$ & 222 & $\mathrm{~N} / \mathrm{A}$ & 4.4 & N/A & 0.3 & N/A & 3.7 & 13.7 & 8.4 \\
\hline $\begin{array}{l}\text { 6c-AlOx/Ni/SiO }{ }_{2} \\
\text { (ALD) }\end{array}$ & 167 & $\mathrm{~N} / \mathrm{A}$ & 3.6 & $\mathrm{~N} / \mathrm{A}$ & 0.2 & $\mathrm{~N} / \mathrm{A}$ & 3 & 19.2 & 8.2 \\
\hline $\begin{array}{l}\text { 3c- } \\
\text { Alucone/Ni/SiO } \\
\text { (MLD) }\end{array}$ & 212 & 318 & 1.2 & 3.78 & 0.23 & 0.33 & 3.7 & 11.2 & 8.5 \\
\hline $\begin{array}{l}\text { 6c- } \\
\text { AluconeNi/SiO } \\
\text { (MLD) }\end{array}$ & 211 & 283 & 1.2 & 4 & 0.23 & 0.32 & 3.3 & 11.2 & 9.6 \\
\hline
\end{tabular}


[a] Specific surface area calculated from BET method. [b] Pore size calculated by NLDFT method. [c] values of pore size and surface area after thermal treatment at $500^{\circ} \mathrm{C}$ in $5 \% \mathrm{H}_{2} / \mathrm{He}$ for $60 \mathrm{~min}$. [d] Elemental analysis carried out XRF

\subsubsection{Hybrid inorganic-organic alucone over-layer via MLD synthesis}

$\mathrm{N}_{2}$ sorption measurements on MLD coated samples (Figure 2a) show type IV isotherms with a $\mathrm{H} 1$ hysteresis loop similar to the results observed for the ALD coated samples. After 3 cycles of MLD the pore size changed significantly from $6.6 \mathrm{~nm}$ to 1.2 $\mathrm{nm}$ as shown in table 1 and figure $2 \mathrm{~b}$. This is due to the larger organic parts present in the overlayer structure forming a thicker hybrid organic-inorganic layer. The bulkier alucone layer is responsible for sudden decrease in specific surface area of MLD modified materials. This is due to blocking of pores due to bulkier ligands of hybrid alucone layer. The porosity and lost surface area can be gained by thermally treating the alucone layer. The thermal treatment at $500^{\circ} \mathrm{C}$ in $5 \% \mathrm{H}_{2} / \mathrm{He}$ to MLD modified samples restored the BET surface area to $318 \mathrm{~m}^{2} / \mathrm{g}$ from $210 \mathrm{~m}^{2} / \mathrm{g}$ for 3 cycle coated MLD sample. The $\mathrm{N}_{2}$ sorption isotherm and pore size distribution curve is shown in figure S2. The gain in surface area after thermal treatment is due to decomposition of organic ligands in alucone layer. This results in formation of porous over-layer on $\mathrm{NiO} / \mathrm{SiO}_{2}$ sample.

The Al content of the MLD coated samples showed no significant difference between the 3 and 6 cycles. Although the MLD process showed self-limiting behaviour in initial cycles, the Al uptake decreased significantly until there was no significant growth of alucone. To investigate this phenomenon, we carried out in-situ mass suspension balance study of the MLD process in a home-built ALD reactor. The detailed description of the ALD set-up is given elsewhere.[38] The mass gain as function of cycle and time can be seen in figure S3. The first cycle of TMA/EG was self-limiting with a total mass gain of $\sim 20 \%$ due to the formed alucone layer. During the second cycle, the TMA uptake showed two features: a strong chemisorption of TMA on a small fraction of the hybrid alucone layer in parallel to a weak physisorption on the majority of the surface. The physisorbed TMA species were removed during the purging step and only chemisorbed TMA species remained on the surface. A similar phenomenon was also observed during the MLD process of TMA and hydroquinone [41]. In the present study, the mass uptake of the half cycle of TMA 
during the second cycle decreased rapidly as compared to first TMA half cycle and during the next subsequent cycles only trace amount of TMA could chemisorb on the surface of alucone coated $\mathrm{SiO}_{2}$. These results are in contrast to studies carried out on a flat $\mathrm{Si}(100)$ substrate in QCM by Dameron et al. [42] . One possible explanation for the hindered aluminum uptake in our case is the use of ethylene glycol as second reactant. In contrast to water as second reactant, the organic precursor maintains a flexible carbon chain, which is likely to bend so that growth is not perfectly perpendicular to surface. Possibly, these ligands can even react twice with several surface groups thereby reducing the number of active sites for chemisorption. The ethylene glycol molecule is also bulky in comparison to the water molecule causing steric hindrance on the surface. Herein, we use porous high surface area silica in contrast to flat $\mathrm{Si}$ wafers with a combination of few micropores, mainly mesopores and some macropores. It is thus highly likely that also some pores will be blocked due to bulky ligands in 2-3 MLD cycles.

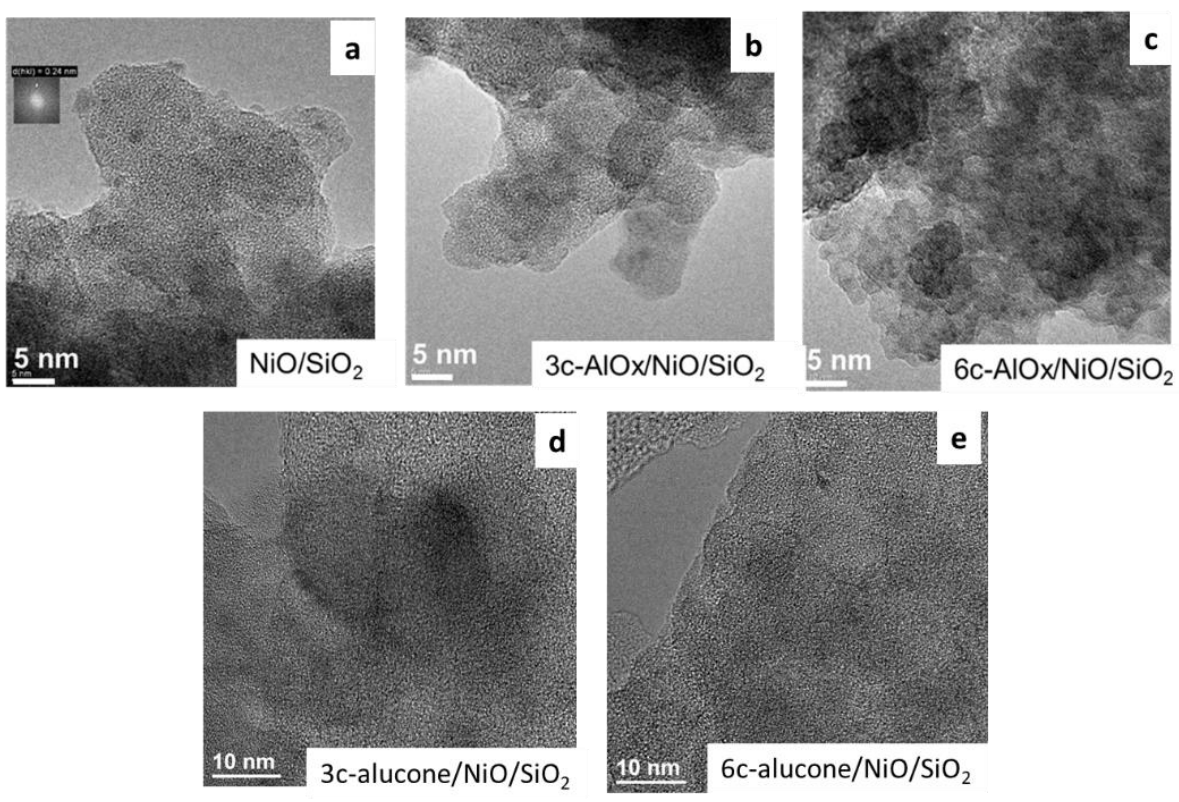

Figure 4. Transmission electron microscopy of pristine as synthesized catalyst (a) $\mathrm{NiO} / \mathrm{SiO}_{2}$, (b) 3-c AlOx/NiO/SiO 2 ALD, (c) 6-c AlOx/NiO/SiO ${ }_{2}$ ALD, (d) 3-c Alucone/NiO/SiO ${ }_{2} \mathrm{MLD}$ and (e) 6-c Alucone/ $\mathrm{NiO} / \mathrm{SiO}_{2} \mathrm{MLD}$.

The X-ray diffraction patterns of alucone deposited $\mathrm{NiO} / \mathrm{SiO}_{2}$ samples are shown in figure $\mathrm{S} 1$. The deposited alucone layer is amorphous as similar to ALD deposited alumina layer. XRF results shows that Ni loadings of MLD coated sample decreased from $5 \%$ for pristine sample to $3.22 \%$ after 6 cycles of MLD layer due to addition of alucone layers on parent $5 \% \mathrm{NiO} / \mathrm{SiO}_{2}$ sample. Figure $4 \mathrm{~d}$ and e show the HRTEM 
images of alucone coated $\mathrm{NiO} / \mathrm{SiO}_{2}$, with a low contrast for $\mathrm{NiO}$ nanoparticles as they are embedded within the hybrid alucone layers. However, it should be noted that larger $\mathrm{NiO}$ particles were not observed on MLD modified samples, indicating the size of $\mathrm{NiO}$ supported on $\mathrm{SiO}_{2}$ is well below $5 \mathrm{~nm}$, similar to that of parent $\mathrm{NiO} / \mathrm{SiO}_{2}$.

\subsection{Catalytic testing:}

The non-coated and ALD/MLD modified catalysts were tested for dry reforming of methane reaction in an 8 bed parallel reactor at a space velocity of $320,000 \mathrm{~mL} / \mathrm{h} / \mathrm{g}$. Each catalyst was in-situ reduced in the reactor in $5 \% \mathrm{H}_{2}$ for $1 \mathrm{~h}$ at $500^{\circ} \mathrm{C}$ prior to the catalytic reaction. The conversion of $\mathrm{CH}_{4}$ and $\mathrm{CO}_{2}$ over time on stream at different temperatures can be seen in figure 5 and $\mathrm{S} 4 . \mathrm{Ni} / \mathrm{SiO}_{2}$ showed higher initial activities at different temperatures; however, the deactivation behaviour can be easily seen during the ramping down phase of the temperature profiles. The catalyst coated with the alumina over-layer using ALD showed little or no conversion at all. This is surprising as previously various studies proved the applicability of thin alumina layers on supported metallic nanoparticles to inhibit their sintering under reaction conditions.

In these cases, a thermal pre-treatment was necessary for restructuring of alumina layer thus to introduce micro-porosity through thermal annealing or burning of residual ligands from TMA. However, majority of the reactions were carried out in between 400$600^{\circ} \mathrm{C}$. We studied the effect of thermal pre-treatment at $700^{\circ} \mathrm{C}$ in synthetic air for the alumina coated $\mathrm{Ni} / \mathrm{SiO}_{2}$ catalysts (shown in figure S4), but no significant increase in activity or stability was observed. Alumina ALD results in a dense alumina layers on top of $\mathrm{Ni} / \mathrm{SiO}_{2}$ which could lead to formation of inactive $\mathrm{NiAl}_{2} \mathrm{O}_{4}$ species, thereby blocking DRM active $\mathrm{Ni}^{\circ}$ sites.

Littlewood et al.[40] studied the issue of $\mathrm{NiAl}_{2} \mathrm{O}_{4}$ formation on $\mathrm{Al}_{2} \mathrm{O}_{3} / \mathrm{Ni} / \mathrm{Al}_{2} \mathrm{O}_{3}$ sandwich catalysts prepared by ALD. Indeed, the formation of spinel aluminates resulted in a material inactive towards DRM. However, in this case the activity of the catalyst could be improved over time on stream at $700^{\circ} \mathrm{C}$ due to the slow reduction of spinel aluminates to $\mathrm{Ni}^{\circ}$. It should be however noted that higher reduction temperatures and longer activation times are not economical or feasible for the development of improved catalysts for DRM. 
a)

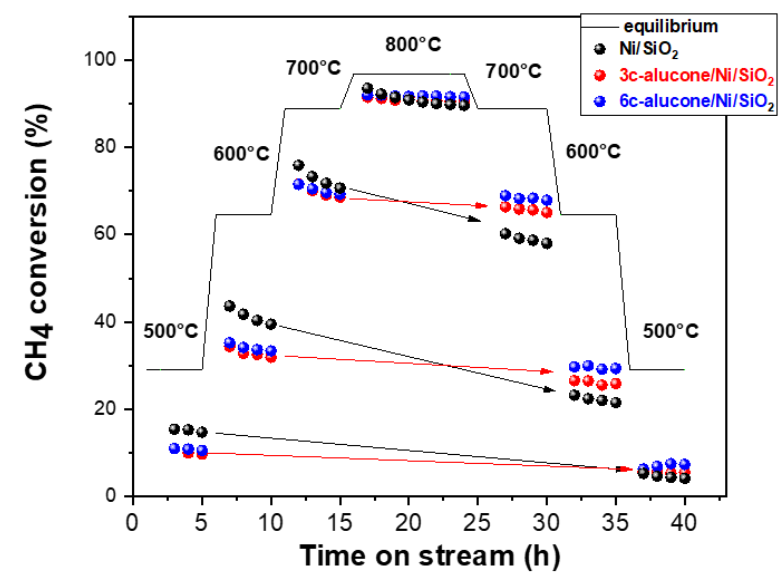

b)

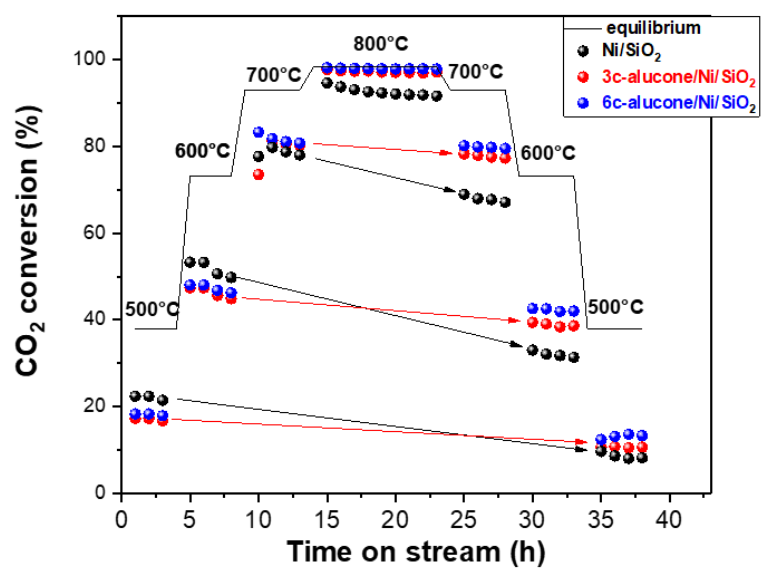

Figure 5 (a) $\mathrm{CH}_{4}$ conversion and (b) $\mathrm{CO}_{2}$ conversion over time at $500^{\circ} \mathrm{C}, 600^{\circ} \mathrm{C}, 700^{\circ} \mathrm{C}$ and $800^{\circ} \mathrm{C}$ in a ramp up and ramp down experiment. DRM was carried out at each temperature for $5 \mathrm{~h}$, space velocity: $320,000 \mathrm{~mL} / \mathrm{h} / \mathrm{g}$.

$\mathrm{Ni} / \mathrm{SiO}_{2}$ coated with different cycles of alucone layers via molecular layer deposition showed initially lower activity as compared to the non-coated catalyst. This can be attributed the lower Ni content in MLD modified catalysts due to addition of the alucone. MLD coated catalysts showed different behaviour in catalytic conditions as compared to ALD modified catalysts. This behaviour was not surprising as the thermal treatment to MLD coated catalysts in-situ at $500^{\circ} \mathrm{C}$ in $5 \% \mathrm{H}_{2} / \mathrm{He}$ stream for $60 \mathrm{~min}$ results in decomposition of organic part of hybrid organic-inorganic layer resulting in formation of porous net-like structure that led to increasing the accessibility of active $\mathrm{Ni}^{\circ}$ species to covert $\mathrm{CO}_{2}$ and $\mathrm{CH}_{4}$. However, during the ramping up period the activity of $\mathrm{Ni} / \mathrm{SiO}_{2}$ catalyst decreased to an extent where the alucone coated catalyst and reference catalyst had similar conversion rates for $\mathrm{CH}_{4}$ and $\mathrm{CO}_{2}$ despite the difference in Ni content of the catalysts.

Initial conversion of methane for the uncoated catalyst at $600^{\circ} \mathrm{C}$ was $39 \%$. After $25 \mathrm{~h}$ time of on stream the reference, catalyst showed the severe deactivation with loss of $45 \%$ of initial activity. In contrast for the 3 and 6 cycles MLD coated catalyst deactivation was much lower, i.e. $18 \%$ and $12 \%$ respectively. This is a significant enhancement in stability by application of just 3 to 6 layers of alucone. The $\mathrm{CO}_{2}$ conversion of all catalyst at $800^{\circ} \mathrm{C}$ reached equilibrium hence the deactivation behaviour cannot be studied at this temperature, as no more methane will be converted by $\mathrm{CO}_{2}$ reforming. However, the deactivation of $\mathrm{Ni} / \mathrm{SiO}_{2}$ catalyst can be prominently seen when the temperature was ramped down again. The $\mathrm{CO}_{2}$ 
conversions for non- and alucone coated $\mathrm{Ni} / \mathrm{SiO}_{2}$ catalyst were slightly higher than the values for $\mathrm{CH}_{4}$ conversion possibly due to a parallel reverse water gas shift reaction $\left(\mathrm{CO}_{2}+\mathrm{H}_{2}=\mathrm{CO}+\mathrm{H}_{2} \mathrm{O}\right)$. TEM measurements of spent catalysts are shown in figure 6 . The $\mathrm{Ni} / \mathrm{SiO}_{2}$ catalyst suffers from strong deactivation due to some sintering and extensive filamentous carbon formation, which detaches and encapsulates the active $\mathrm{Ni}^{\circ}$ from the surface of the support. Filamentous carbon formation occurs when the $\mathrm{Ni}$ nanoparticle size is in range of 7-10 nm [43]. The Ni nanoparticles sintered during dry reforming of methane from initial average diameter of $5 \mathrm{~nm}$. The sintering was higher for uncoated samples as compared to 3 and 6 MLD cycle coated catalysts indicating from broader particle size distribution in figure $5 \mathrm{e}$. The carbon content of spent catalysts was quantified using $\mathrm{CHN}$ analysis, the results are shown in figure 6e. The reference $\mathrm{Ni} / \mathrm{SiO}_{2}$ samples had a carbon content of $7.6 \%$ after $40 \mathrm{~h}$ time on stream. For catalysts modified via MLD, the overall carbon content after catalytic testing decreased by factor of nearly 10 to $0.8 \%$ carbon. The significant decrease in carbon agglomeration occurs together with suppression of whisker carbon formation. No carbon filaments were found in the micrographs of spent MLD catalysts.

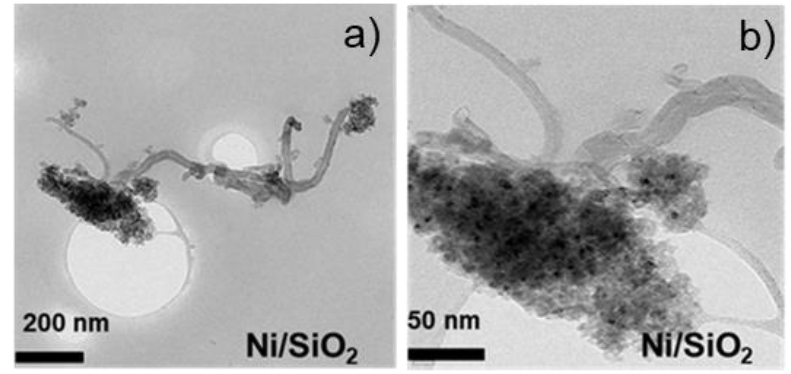

e)

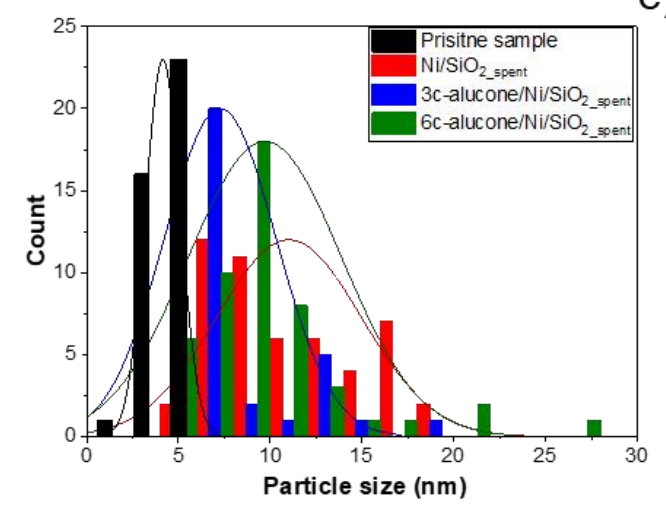

b)

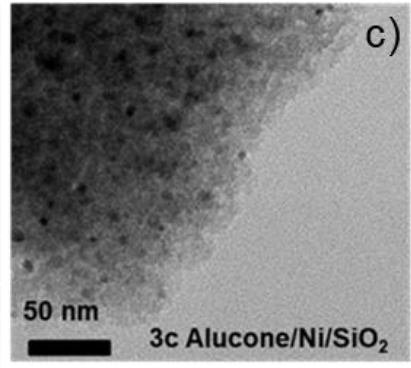

c)

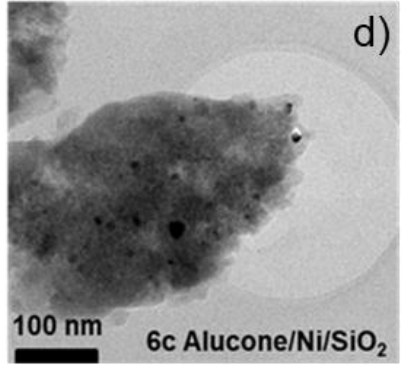

f)

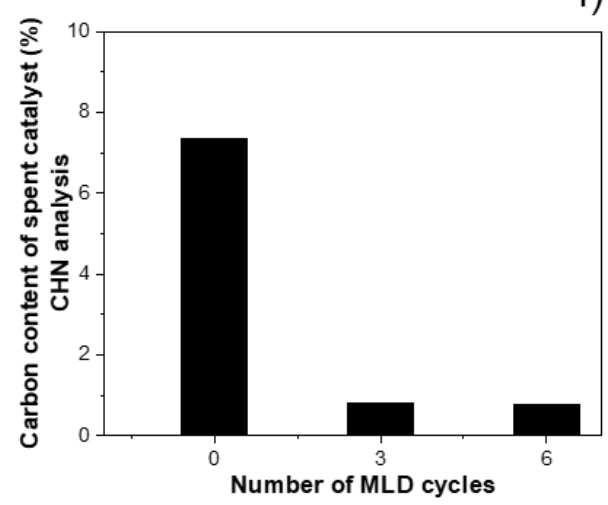

Figure 6 Transmission electron microscopy of spent catalyst $(a, b) \mathrm{Ni} / \mathrm{SiO}_{2}$ (c) 3-cycle Alucone/Ni/SiO ${ }_{2}$ MLD (d) 6-cycle Alucone/Ni/SiO ${ }_{2} \mathrm{MLD}_{\text {, (e) }}$ Particle size distribution of spent and fresh catalyst samples, and (f) $\mathrm{CHN}$ analysis of spent catalyst indicating carbon content (coke deposition). 
Recently Cao et al.,[44] published work on the selective tailoring on $\mathrm{Ni}$ nanoparticles supported on alumina by atomic layer deposition of Co. The formed Co decorated Ni surface was active and stable towards dry reforming of methane at higher temperature. Cao et al.,[44] showed that extremely low Co loadings ( 0.5 wt.\%) were enough to tailor the $\mathrm{Ni}$-Co interface, this resulted in coke stable catalyst by passivation and isolation of coke sites on $\mathrm{Ni}$. In our approach, we required $\mathrm{AlOx}$ loading as high as $13 \%$ to stabilize the $\mathrm{Ni}$ nanoparticles under harsh dry reforming conditions. We hypothesized that, the inhibition in filamentous carbon formation was result of surface modification of Ni nanoparticles by formed porous AIOx layer after decomposition of the organic part of aluminium alkoxide shell during the reductive pre-treatment under $\mathrm{H}_{2}$ reductive condition at $500^{\circ} \mathrm{C}$. To support this hypothesis, we carried out TG-MS experiments in a flow of a $5 \% \mathrm{H}_{2} / \mathrm{He}$ gas mixture. The results are shown figure 7 . We observed an overall mass decrease of $14.5 \%$ for the $6 \mathrm{MLD}$ cycle coated $\mathrm{NiO} / \mathrm{SiO}_{2}$ sample in the temperature range of $100-500^{\circ} \mathrm{C}$ (after removal of physisorbed water). Comparing this mass loss observed in TG-MS to the mass gain achieved during ethylene glycol half cycles for the alucone growth on $\mathrm{NiO} / \mathrm{SiO}_{2}$ (shown in figure S3), we can assume removal of a vast majority of organic ligands. An additional mass loss of $1.3 \%$ can be rationalized by reduction of $\mathrm{NiO}$ to $\mathrm{Ni}$. The mass loss is already a clear indication for removal of organic ligands and reduction of $\mathrm{NiO}$ in reductive atmosphere at $500^{\circ} \mathrm{C}$. The online mass spectrometry signals of the TG-MS experiment using the $6 \mathrm{MLD}$ cycle coated $\mathrm{NiO} / \mathrm{SiO}_{2}$ is shown is figure $7 \mathrm{~b}$. For clarity, only masse traces for $\mathrm{m} / \mathrm{z}=15,18$, and 28 are shown. We would assign $\mathrm{m} / \mathrm{z}=18$ to water, $\mathrm{m} / \mathrm{z}=15$ to methane, and $\mathrm{m} / \mathrm{z}=28$ to ethane. These assignments are supported by other mass traces, e.g. 16, 27, 29, and 30 shown in the supplementary information, figure S6. Another indication for the removal of the organic ligands is the fact that the reduction at $500^{\circ} \mathrm{C}$ in $5 \% \mathrm{H}_{2} / \mathrm{He}$ increases the porosity and the specific surface area compared to the state after MLD. The average pore volume and surface area of $6 \mathrm{c}$ alucone $/ \mathrm{NiO} / \mathrm{SiO}_{2}$ was changed from $0.23 \mathrm{~mL} / \mathrm{g}$ and $211 \mathrm{~m}^{2} / \mathrm{g}$ to $0.32 \mathrm{~mL} / \mathrm{g}$ and 283 $\mathrm{m}^{2} / \mathrm{g}$ after the reductive thermal treatment. Hence the specialised combination of oxidation-reduction treatment was not necessary to form porous layer as indicated by Gould et al. [36]. The utilisation of initial oxidation treatment for burning of sacrificial organic ligands will also oxidize the $\mathrm{Ni}$ nanoparticles supported on $\mathrm{Al}_{2} \mathrm{O}_{3}$ possibly forming $\mathrm{NiAl}_{2} \mathrm{O}_{4}$. This might explain the slow increase in activity of their ABC type MLD coated $\mathrm{Ni} / \mathrm{Al}_{2} \mathrm{O}_{3}$ catalyst under DRM conditions. 
a)

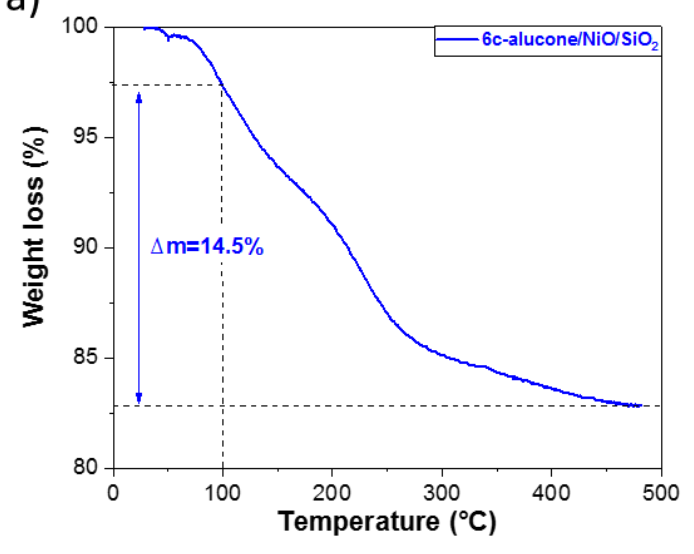

b)

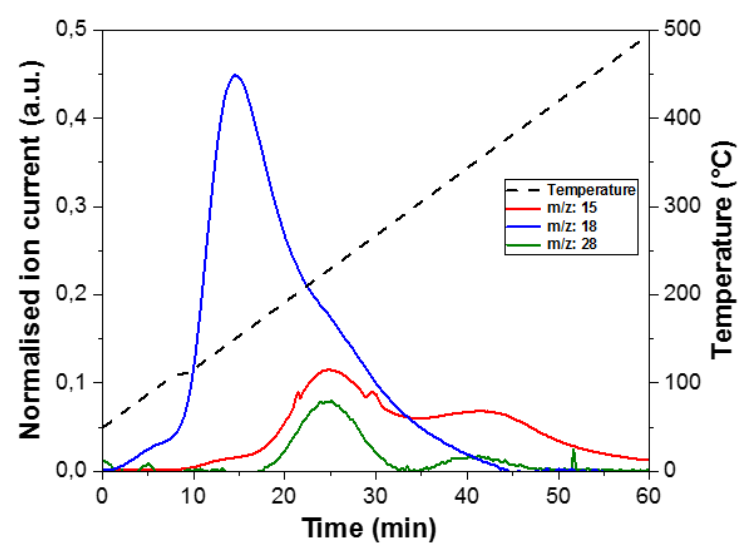

Figure 7. TG-MS analysis of MLD modified $6 \mathrm{c}$-alucone/NiO/SiO $/ 2$ samples under $5 \% \mathrm{H}_{2} / \mathrm{He}$ atmosphere.

Shang et. al. [45] reported the formation of $\mathrm{NiAl}_{2} \mathrm{O}_{4}$ phase after $\mathrm{ALD}$ of $\mathrm{Ni}$ on porous $\mathrm{Al}_{2} \mathrm{O}_{3}$ support. This catalyst showed stable performance on time on stream however required the higher reduction temperatures and longer time for activation of catalyst. Although alumina is better choice of support for Ni nanoparticles employed in DRM due to stronger metal support interaction, the formation of aluminates is unavoidable. In contrast, $\mathrm{SiO}_{2}$ with its inherent high surface area and porosity, could be utilized as catalyst support for $\mathrm{Ni}$ nanoparticles in DRM. The use of overcoating $\mathrm{Ni} / \mathrm{SiO}_{2}$ overcomes the problem of aluminate formation and subsequent complex process of activation of nickel catalysts while providing stable and active performance under DRM conditions. Surface modification of $\mathrm{Ni}$ by protective porous $\mathrm{AlOx}$ layer formed by thermal decomposition of alucone is responsible for confining the metal nanoparticles and thus limit filamentous carbon formation. In summary the stabilization against sintering and filamentous carbon formation are crucial factors, which lead to high stability and activity of alucone, coated $\mathrm{Ni} / \mathrm{SiO}_{2}$ catalyst via molecular layer deposition.

\subsection{Conclusions}

Alumina and alucone coated $\mathrm{Ni} / \mathrm{SiO}_{2}$ catalysts were successfully synthesized via atomic and molecular layer deposition. The ALD modified $\mathrm{Ni} / \mathrm{SiO}_{2}$ catalyst were inactive towards dry reforming of methane supposedly due to formation of inactive $\mathrm{NiAl}_{2} \mathrm{O}_{4}$, while MLD modified $\mathrm{Ni} / \mathrm{SiO}_{2}$ catalysts showed an impressive activity and 
stability under harsh DRM conditions. The hybrid organic inorganic alucone layer is suitable for formation of protective coatings because at higher temperature. The organic moieties in the alucone layer decompose to form a porous protective layer. Surprisingly only $3 \mathrm{MLD}$ cycles were enough for the stabilization of the $\mathrm{Ni} / \mathrm{SiO}_{2}$ catalyst at higher DRM operation temperature. This strategy can be further applied to other reactions where reaction dynamics are driven by need of sinter-stable and coke stable catalyst.

\section{Acknowledgement}

This work was conducted in the framework of the BasCat - UniCat BASF JointLab at the Technische Universität Berlin. The authors are grateful for support by the Einstein Foundation Berlin (ESB) - Einstein Center of Catalysis (EC2). The work was funded by the Deutsche Forschungsgemeinschaft (DFG, German Research Foundation) under Germany's Excellence Strategy - EXC 2008 - 390540038" - UniSysCat. Authors thank Dr. Selve Sören (TU Berlin, ZELMI), Marian Unterweger (TU Berlin), Christina Eichenauer (TU Berlin), Dr. Olaf Timpe (Fritz-Haber-Institut, Berlin) for assistance in characterisation of materials.

\section{References}

[1] J.H. Lunsford, Catalytic conversion of methane to more useful chemicals and fuels: A challenge for the 21st century, Catal. Today. 63 (2000) 165-174. https://doi.org/10.1016/S0920-5861(00)00456-9.

[2] J.-M. Lavoie, Review on dry reforming of methane, a potentially more environmentally-friendly approach to the increasing natural gas exploitation., Front. Chem. 2 (2014) 81. https://doi.org/10.3389/fchem.2014.00081.

[3] M.S. Fan, A.Z. Abdullah, S. Bhatia, Catalytic technology for carbon dioxide reforming of methane to synthesis gas, ChemCatChem. 1 (2009) 192-208. https://doi.org/10.1002/cctc.200900025.

[4] J.R. Rostrup-Nielsen, Production of synthesis gas, Catal. Today. 18 (1993) 305-324. https://doi.org/10.1016/0920-5861(93)80059-A.

[5] K. Aasberg-Petersen, J.H. Bak Hansen, T.S. Christensen, I. Dybkjaer, P.S. Christensen, C. Stub Nielsen, S.E.L. Winter Madsen, J.R. Rostrup-Nielsen, 
Technologies for large-scale gas conversion, Appl. Catal. A Gen. 221 (2001) 379-387. https://doi.org/10.1016/S0926-860X(01)00811-0.

[6] H.S. Bengaard, J.K. Nørskov, J. Sehested, B.S. Clausen, L.P. Nielsen, A.M. Molenbroek, J.R. Rostrup-Nielsen, Steam reforming and graphite formation on Ni catalysts, J. Catal. 209 (2002) 365-384.

https://doi.org/10.1006/jcat.2002.3579.

[7] V.R. Choudhary, A.M. Rajput, B. Prabhakar, Energy efficient methane-tosyngas conversion with low $\mathrm{H} 2 / \mathrm{CO}$ ratio by simultaneous catalytic reactions of methane with carbon dioxide and oxygen, Catal. Letters. 32 (1995) 391-396. https://doi.org/10.1007/BF00813234.

[8] Y. Kathiraser, U. Oemar, E.T. Saw, Z. Li, S. Kawi, Kinetic and mechanistic aspects for $\mathrm{CO} 2$ reforming of methane over Ni based catalysts, Chem. Eng. J. 278 (2015) 62-78. https://doi.org/10.1016/j.cej.2014.11.143.

[9] W.J. Jang, J.O. Shim, H.M. Kim, S.Y. Yoo, H.S. Roh, A review on dry reforming of methane in aspect of catalytic properties, Catal. Today. 324 (2019) 15-26. https://doi.org/10.1016/j.cattod.2018.07.032.

[10] H.Y. Wang, E. Ruckenstein, Carbon dioxide reforming of methane to synthesis gas over supported rhodium catalysts: The effect of support, Appl. Catal. A Gen. 204 (2000) 143-152. https://doi.org/10.1016/S0926-860X(00)00547-0.

[11] A.M. O'Connor, Y. Schuurman, J.R.H. Ross, C. Mirodatos, Transient studies of carbon dioxide reforming of methane over Pt/ZrO2 and Pt/Al2O3, Catal. Today. 115 (2006) 191-198. https://doi.org/10.1016/j.cattod.2006.02.051.

[12] M. Wisniewski, A. Boréave, P. Gélin, Catalytic $\mathrm{CO} 2$ reforming of methane over Ir/Ce0.9 Gd0.1O2-x, Catal. Commun. 6 (2005) 596-600. https://doi.org/10.1016/j.catcom.2005.05.008.

[13] L.C.P.F. Júnior, S. de Miguel, J.L.G. Fierro, M. do Carmo Rangel, Evaluation of Pd/La2O3 catalysts for dry reforming of methane, Stud. Surf. Sci. Catal. 167 (2007) 499-504. https://doi.org/10.1016/S0167-2991(07)80181-9.

[14] C. Carrara, J. Múnera, E.A. Lombardo, L.M. Cornaglia, Kinetic and Stability Studies of Ru/La2O3 Used in the Dry Reforming of Methane, Top. Catal. 51 
(2008) 98-106. https://doi.org/10.1007/s11244-008-9131-y.

[15] S. Kawi, Y. Kathiraser, J. Ni, U. Oemar, Z. Li, E.T. Saw, Progress in Synthesis of Highly Active and Stable Nickel-Based Catalysts for Carbon Dioxide Reforming of Methane, ChemSusChem. 8 (2015) 3556-3575. https://doi.org/10.1002/cssc.201500390.

[16] X. Xie, T. Otremba, P. Littlewood, R. Schomäcker, A. Thomas, One-pot synthesis of supported, nanocrystalline nickel manganese oxide for dry reforming of methane, ACS Catal. 3 (2013) 224-229. https://doi.org/10.1021/cs3003963.

[17] P. Littlewood, X. Xie, M. Bernicke, A. Thomas, R. Schomäcker,

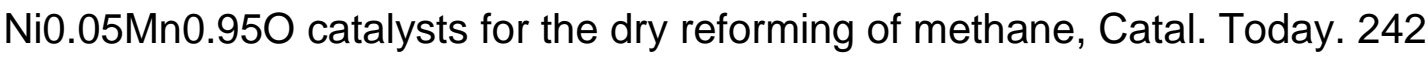
(2015) 111-118. https://doi.org/10.1016/j.cattod.2014.07.054.

[18] The Linde Group, Innovative dry reforming process, (2015) 1. https://www.linde-engineering.com/en/innovations/innovate-dryreforming/index.html (accessed October 7, 2019).

[19] BASF, Innovations for a climate-friendly chemical production, (2019) 1. https://www.basf.com/global/en/media/news-releases/2019/01/p-19-103.html (accessed October 8, 2019).

[20] J.M. Ginsburg, J. Piña, T. El Solh, H.I. De Lasa, Coke formation over a nickel catalyst under methane dry reforming conditions: Thermodynamic and kinetic models, Ind. Eng. Chem. Res. 44 (2005) 4846-4854. https://doi.org/10.1021/ie0496333.

[21] D. Kang, H.S. Lim, J.W. Lee, Enhanced catalytic activity of methane dry reforming by the confinement of $\mathrm{Ni}$ nanoparticles into mesoporous silica, Int. J. Hydrogen Energy. 42 (2017) 11270-11282. https://doi.org/10.1016/j.ijhydene.2017.02.042.

[22] C.J. Liu, J. Ye, J. Jiang, Y. Pan, Progresses in the preparation of coke resistant Ni-based catalyst for steam and $\mathrm{CO} 2$ reforming of methane, ChemCatChem. 3 (2011) 529-541. https://doi.org/10.1002/cctc.201000358.

[23] L.A. Schulz, L.C.S. Kahle, K.H. Delgado, S.A. Schunk, A. Jentys, O. 
Deutschmann, J.A. Lercher, On the coke deposition in dry reforming of methane at elevated pressures, Appl. Catal. A Gen. 504 (2015) 599-607. https://doi.org/10.1016/j.apcata.2015.03.002.

[24] P.M. Arnal, M. Comotti, F. Schüth, High-Temperature-Stable Catalysts by Hollow Sphere Encapsulation, Angew. Chemie Int. Ed. 45 (2006) 8224-8227. https://doi.org/10.1002/anie.200603507.

[25] Z. Bian, S. Kawi, Sandwich-Like Silica@Ni@Silica Multicore-Shell Catalyst for the Low-Temperature Dry Reforming of Methane: Confinement Effect Against Carbon Formation, ChemCatChem. 10 (2018) 320-328. https://doi.org/10.1002/cctc.201701024.

[26] M. Seipenbusch, A. Binder, Structural stabilization of metal nanoparticles by chemical vapor deposition-applied silica coatings, J. Phys. Chem. C. 113 (2009) 20606-20610. https://doi.org/10.1021/jp9063998.

[27] H. Yi, H. Du, Y. Hu, H. Yan, H.L. Jiang, J. Lu, Precisely Controlled Porous Alumina Overcoating on Pd Catalyst by Atomic Layer Deposition: Enhanced Selectivity and Durability in Hydrogenation of 1,3-Butadiene, ACS Catal. 5 (2015) 2735-2739. https://doi.org/10.1021/acscatal.5b00129.

[28] M. Leskelä, M. Ritala, Atomic Layer Deposition Chemistry: Recent Developments and Future Challenges, Angew. Chemie Int. Ed. 42 (2003) 5548-5554. https://doi.org/10.1002/anie.200301652.

[29] S.M. George, Atomic layer deposition: An overview, Chem. Rev. 110 (2010) 111-131. https://doi.org/10.1021/cr900056b.

[30] X. Meng, An overview of molecular layer deposition for organic and organicinorganic hybrid materials: Mechanisms, growth characteristics, and promising applications, J. Mater. Chem. A. 5 (2017) 18326-18378. https://doi.org/10.1039/c7ta04449f.

[31] H. Feng, J. Lu, P.C. Stair, J.W. Elam, Alumina over-coating on Pd nanoparticle catalysts by atomic layer deposition: Enhanced stability and reactivity, Catal. Letters. 141 (2011) 512-517. https://doi.org/10.1007/s10562-011-0548-8.

[32] J. Lu, B. Fu, M.C. Kung, G. Xiao, J.W. Elam, H.H. Kung, P.C. Stair, Coking- 
and Sintering-Resistant Palladium Catalysts Achieved Through Atomic Layer Deposition, Science (80-. ). 335 (2012) 1205-1208.

https://doi.org/10.1126/science.1212906.

[33] E. Baktash, P. Littlewood, R. Schomäcker, A. Thomas, P.C. Stair, Alumina coated nickel nanoparticles as a highly active catalyst for dry reforming of methane, Appl. Catal. B Environ. 179 (2015) 122-127.

https://doi.org/10.1016/j.apcatb.2015.05.018.

[34] X. Liang, M. Yu, J. Li, Y.B. Jiang, A.W. Weimer, Ultra-thin microporousmesoporous metal oxide films prepared by molecular layer deposition (MLD), Chem. Commun. 0 (2009) 7140-7142. https://doi.org/10.1039/b911888h.

[35] X. Liang, J. Li, M. Yu, C.N. McMurray, J.L. Falconer, A.W. Weimer, Stabilization of supported metal nanoparticles using an ultrathin porous shell, ACS Catal. 1 (2011) 1162-1165. https://doi.org/10.1021/cs200257p.

[36] T.D. Gould, A. Izar, A.W. Weimer, J.L. Falconer, J.W. Medlin, Stabilizing Ni catalysts by molecular layer deposition for harsh, dry reforming conditions, ACS Catal. 4 (2014) 2714-2717. https://doi.org/10.1021/cs500809w.

[37] S. Qiu, Q. Zhang, W. Lv, T. Wang, Q. Zhang, L. Ma, Simply packaging Ni nanoparticles inside SBA-15 channels by co-impregnation for dry reforming of methane, RSC Adv. 7 (2017) 24551-24560.

https://doi.org/10.1039/c7ra00149e.

[38] V.E. Strempel, R. Naumann D’Alnoncourt, M. Driess, F. Rosowski, Atomic layer deposition on porous powders with in situ gravimetric monitoring in a modular fixed bed reactor setup, Rev. Sci. Instrum. 88 (2017). https://doi.org/10.1063/1.4992023.

[39] V.E. Strempel, K. Knemeyer, R.N. D'Alnoncourt, M. Driess, F. Rosowski, Investigating the trimethylaluminium/water ALD process on mesoporous silica by in situ gravimetric monitoring, Nanomaterials. 8 (2018). https://doi.org/10.3390/nano8060365.

[40] P. Littlewood, S. Liu, E. Weitz, T.J. Marks, P.C. Stair, Ni-alumina dry reforming catalysts: Atomic layer deposition and the issue of Ni aluminate, Catal. Today. 
(2019). https://doi.org/10.1016/j.cattod.2019.03.040.

[41] D. Choudhury, S.K. Sarkar, N. Mahuli, Molecular layer deposition of alucone films using trimethylaluminum and hydroquinone, J. Vac. Sci. Technol. A Vacuum, Surfaces, Film. 33 (2014) 01A115. https://doi.org/10.1116/1.4900934.

[42] A.A. Dameron, D. Seghete, B.B. Burton, S.D. Davidson, A.S. Cavanagh, J.A. Bertrand, S.M. George, Molecular layer deposition of alucone polymer films using trimethylaluminum and ethylene glycol, Chem. Mater. 20 (2008) 33153326. https://doi.org/10.1021/cm7032977.

[43] J.H. Kim, D.J. Suh, T.J. Park, K.L. Kim, Effect of metal particle size on coking during $\mathrm{CO} 2$ reforming of $\mathrm{CH} 4$ over Ni-alumina aerogel catalysts, Appl. Catal. A Gen. 197 (2000) 191-200. https://doi.org/10.1016/S0926-860X(99)00487-1.

[44] K. Cao, M. Gong, J. Yang, J. Cai, S. Chu, Z. Chen, B. Shan, R. Chen, Nickel catalyst with atomically-thin meshed cobalt coating for improved durability in dry reforming of methane, J. Catal. 373 (2019) 351-360. https://doi.org/10.1016/j.jcat.2019.04.017.

[45] Z. Shang, S. Li, L. Li, G. Liu, X. Liang, Highly active and stable alumina supported nickel nanoparticle catalysts for dry reforming of methane, Appl. Catal. B Environ. 201 (2017) 302-309. https://doi.org/10.1016/j.apcatb.2016.08.019. 
Supplementary Information: Design of an active and stable catalyst for dry reforming of methane via molecular layer deposition

Piyush Ingale a, Chengyue Guan a , Ralph Kraehnert a, Raoul Naumann d'Alnoncourt $\mathrm{a}^{*}$, Arne Thomas ${ }^{\mathrm{b}}$ and Frank Rosowski ${ }^{\mathrm{a}, \mathrm{c}}$

a BasCat - UniCat BASF JointLab, Technische Universität Berlin, Berlin 10623, Germany

${ }^{b}$ Functional Materials, Department of Chemistry, Technische Universität Berlin, Berlin 10623, Germany

'BASF SE, Process Research and Chemical Engineering, Heterogeneous catalysis, Ludwigshafen 67056, Germany

\section{r.naumann@bascat.tu-berlin.de}

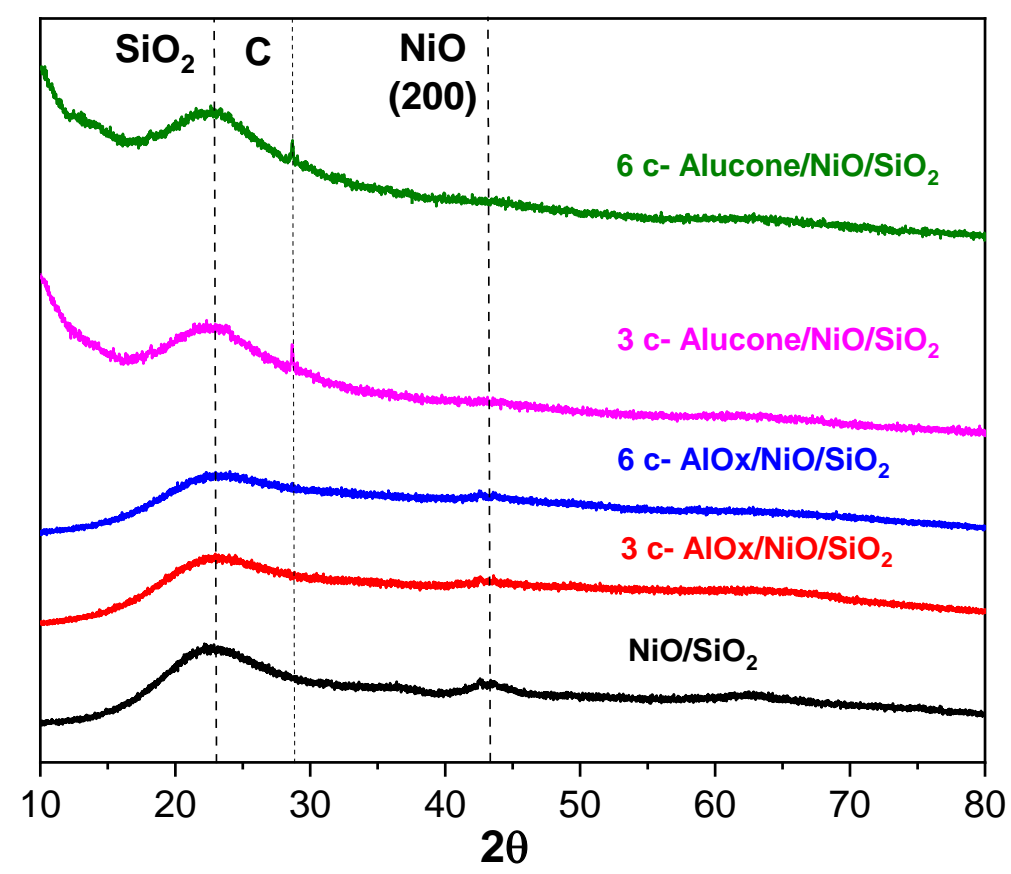

Figure S1. XRD patterns of ALD and MLD modified materials. 

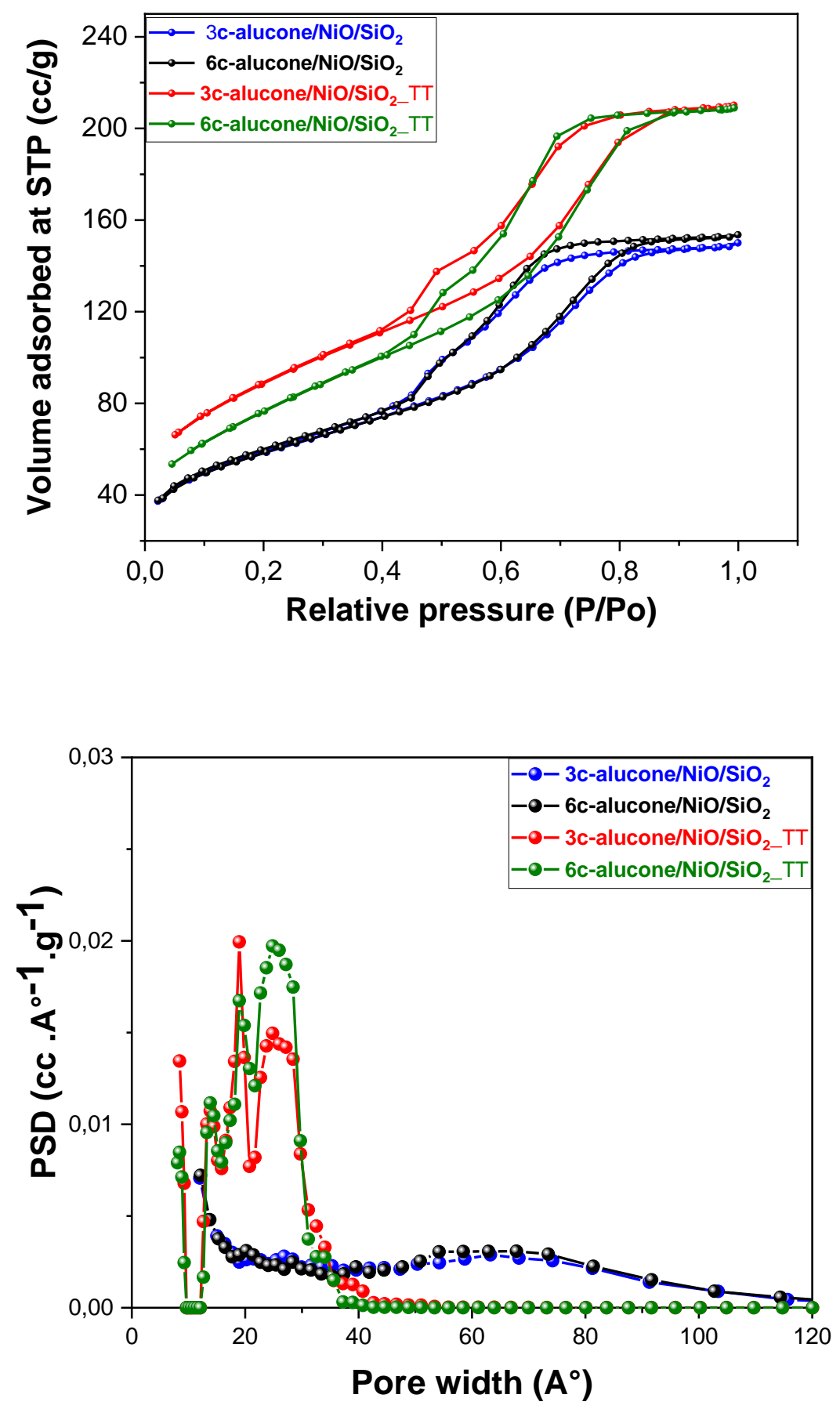

Figure S2. $\mathrm{N}_{2}$ sorption isotherm and pore size distribution calculated from NLDFT method for MLD coated samples. The samples indicating TT are the MLD coated samples after thermal treatment in $5 \% \mathrm{H}_{2} / \mathrm{He}$ at $500^{\circ} \mathrm{C}$ for $30 \mathrm{~min}$. 


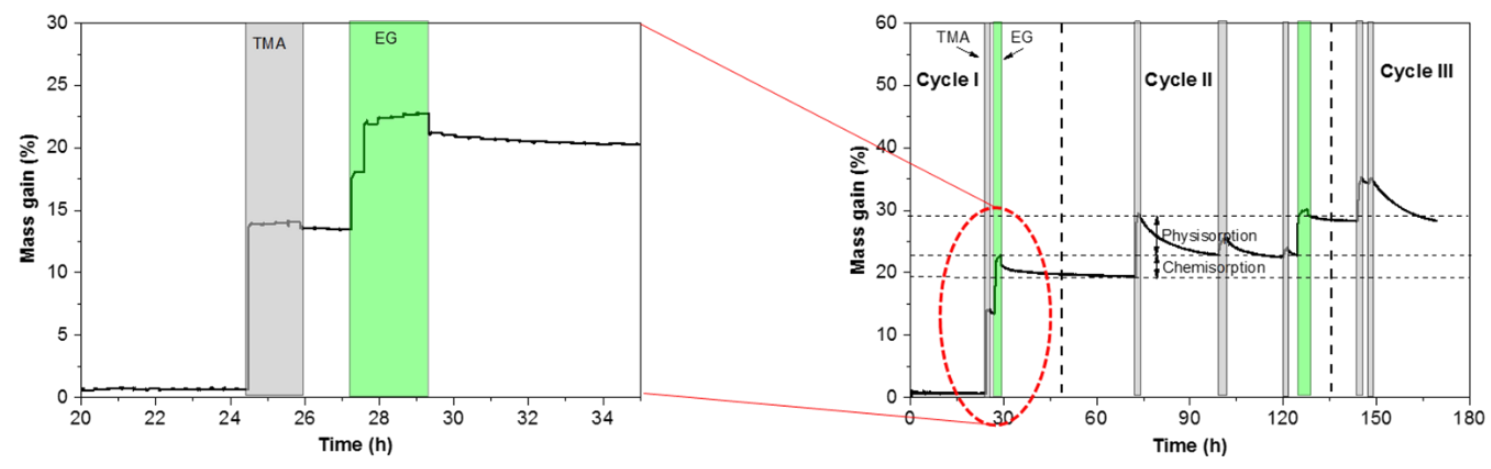

Figure S3. In situ mass gain analysis of TMA/EG MLD process in magnetic suspension balance. Deposition temperature was $150^{\circ} \mathrm{C}$ and flow of carrier gases were adjusted at 50 $\mathrm{mL} / \mathrm{min}$. 

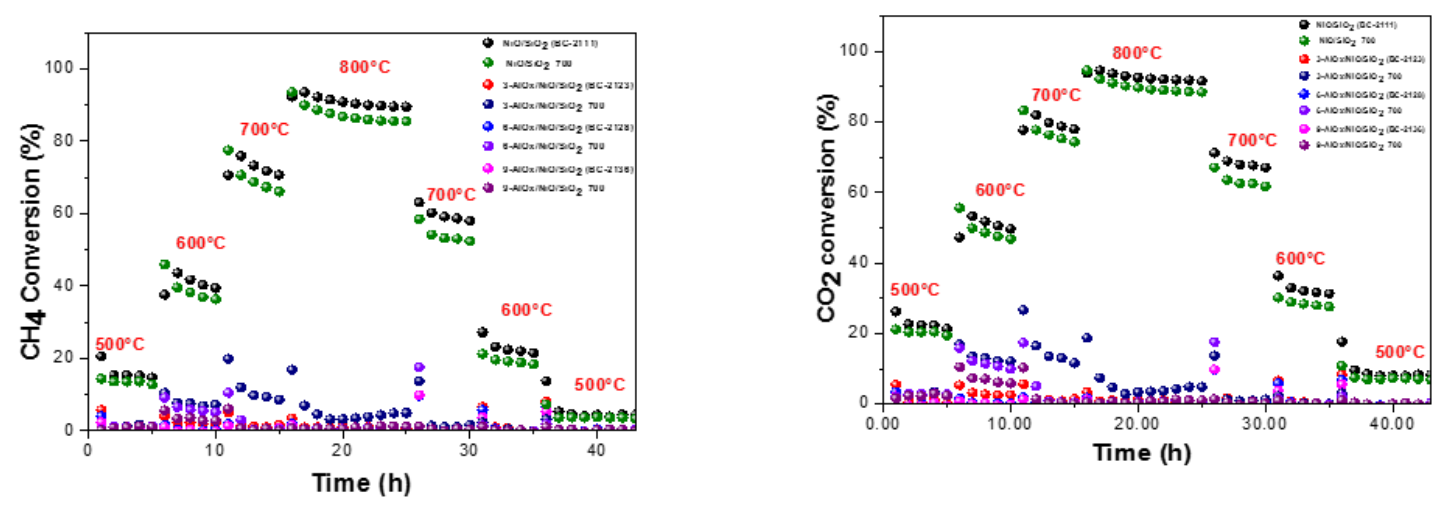

Figure S4. Effect of thermal pre-treatment at $700^{\circ} \mathrm{C}$ on alumina coated $\mathrm{Ni} / \mathrm{SiO}_{2}$ via ALD technique. There was evidence of minor increase in activity however; the catalysts were not stable over time on stream. 


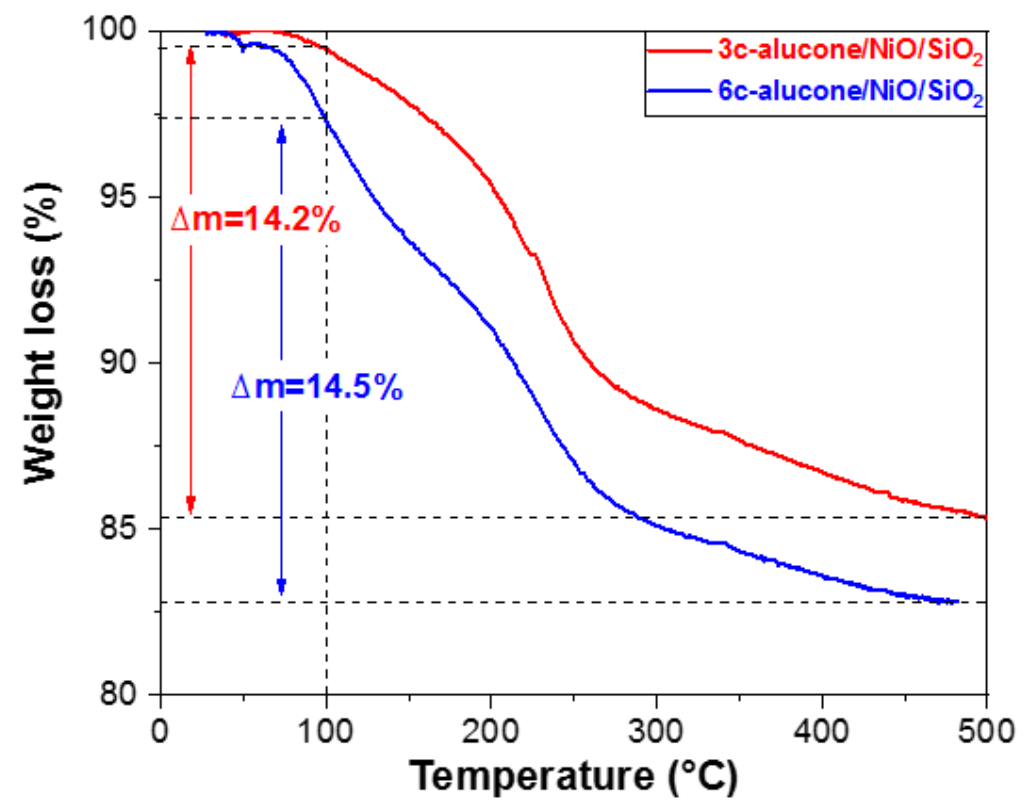

Figure S5. TGA analysis of 3 and 6 cycle MLD coated NiO/SiO2 catalyst under reductive flow of $80 \mathrm{~mL} / \mathrm{min}$ of $5 \% \mathrm{H}_{2} / \mathrm{He}$. 


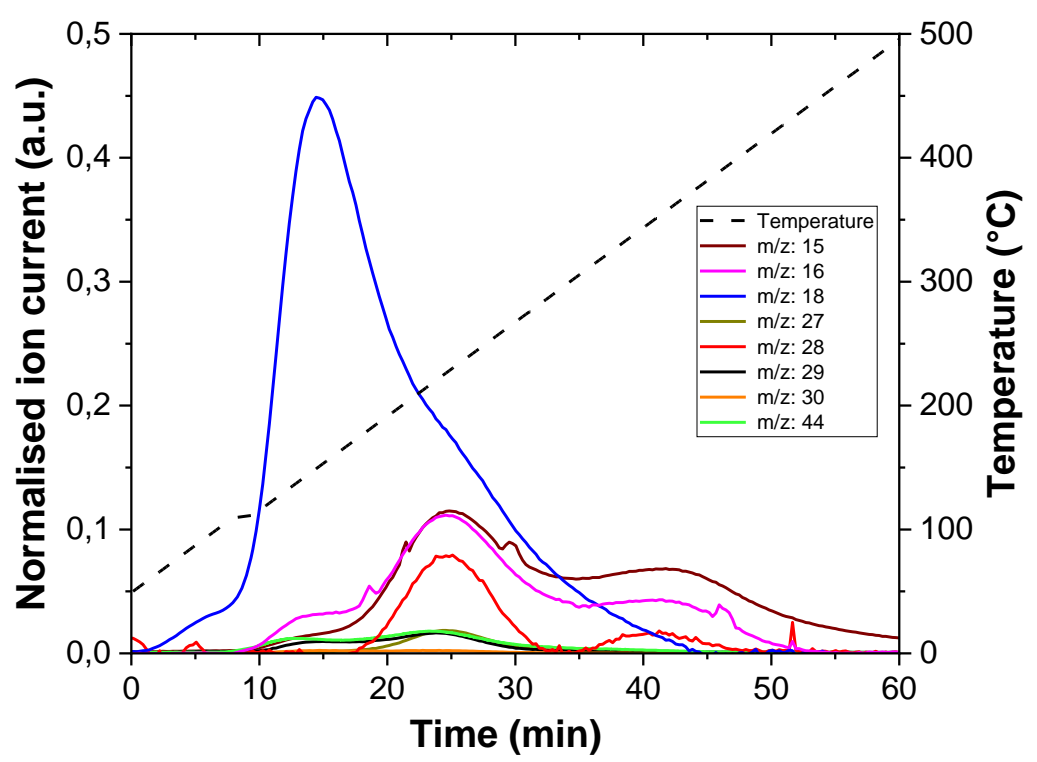

Figure S6. Complete normalised $\mathrm{m} / \mathrm{z}$ ratios during $\mathrm{In}$-situ mass spectroscopy analysis of TG$\mathrm{MS}$ of $6 \mathrm{c}$-alucone/NiO/SiO${ }_{2}$ under reductive flow of $80 \mathrm{~mL} / \mathrm{min}$ of $5 \% \mathrm{H}_{2} / \mathrm{He}$. 